\section{Por uma sociologia da autoajuda: o esboço de sua legitimação na sociedade contemporânea}

\author{
Toward a sociology of \\ self-help: an outline of \\ its legitimacy in \\ contemporary society
}

Elaine da Silveira Leite ${ }^{i}$

i Professora, Programa de Pós-graduação em Sociologia, Departamento de Sociologia e Política/Universidade Federal de Pelotas. Pelotas - RS - Brasil

orcid.org/0000-0003-1402-3839

elaineleite10@gmail.com

Recebido em 21 out. 2017.

Aprovado em 15 maio 2018.
LEITE, Elaine da Silveira. Por uma sociologia da autoajuda: o esboço de sua legitimação na sociedade contemporânea. História, Ciências, Saúde - Manguinhos, Rio de Janeiro, v.26, n.3, jul.-set. 2019, p.917-932.

\section{Resumo}

Este artigo tem como objetivo revisar o tema da autoajuda, esquematizando a origem do conceito e sua ligação com temáticas cotidianas e ramos acadêmicos responsáveis pela construção desse fenômeno. Para isso, o ponto de partida é o pensamento de intelectuais que procuram expor como a autoajuda acompanha o percurso do mundo do trabalho e do sistema capitalista, apropriando-se de artifícios de legitimação. Busca-se apontar caminhos pelos quais é possível abordar a temática da autoajuda para além de sua crítica como literatura supérflua.

Palavras-chave: autoajuda; legitimação; sociologia.

\section{Abstract}

This article reviews the topic of self-help, from the origin of this concept to its connection with everyday themes, as well as the branches of academia responsible for the construction of this phenomenon. The starting point in this process is intellectual thinking meant to show how self-help is present in the world of work and the capitalist system, appropriating methods of legitimation. Ways of addressing the topic of self-help are sought out, beyond its critiques as superfluous literature.

Keywords: self-help; legitimation; sociology. 


\section{A autoajuda e seu sentido de conformação moral}

Em épocas anteriores da história ocidental, os livros religiosos bastavam para explicar o mundo e prescrever formas de conduta (Elias, 1994; Rüdiger, 1996). Hoje os livros de autoajuda conquistaram espaço nas livrarias, oferecendo aos leitores uma suposta fórmula para auxiliar o homem moderno a encontrar alívio e orientação, como afirma Rüdiger (1996).

Em geral, as pesquisas acadêmicas sobre autoajuda apontam o livro Self-Help, publicado em 1859, por Samuel Smiles (1812-1904), como o texto que deu origem a esse fenômeno. Self-Help é um manual que buscava ensinar à classe operária como adaptar-se ao mundo organizacional em formação daquela época e com isso alcançar o sucesso individual. Para Smiles, o mundo do trabalho é um dos principais educadores do caráter; portanto, a felicidade e o sucesso não se restringem a conseguir qualquer coisa na vida, mas são essenciais para a formação do bom caráter (Rüdiger, 1996; Magro, Martelli, 2006; Brunhelli, 2004).

Os melhores resultados na vida geralmente são obtidos por meios simples e pelo exercício de qualidades habituais. A vida comum do dia a dia, com seus cuidados, necessidades e deveres, fornece ampla oportunidade para adquirir o melhor tipo de experiência; e seus caminhos mais batidos fornecem ao verdadeiro trabalhador um amplo espaço para o esforço e o aprimoramento pessoal. A estrada do bem-estar humano está junto à velha rodovia da firme virtude; e aqueles que forem mais persistentes e trabalharem no espírito mais verdadeiro em geral serão os mais bem sucedidos (Smiles, 1859, p.94). ${ }^{1}$

Ao fazer uma revisão das origens da autoajuda, Martelli (2006) ressalta que, após a grande influência do livro de Smiles, o homem passa a ser concebido como um ser que, em vez de desejos, tem deveres: ele vence quando concretiza algo e apresenta uma existência laboriosa, e não quando obtém satisfação com êxitos parciais, conforme o excerto acima.

Para Bosco (2001, p.6), Smiles avigora a ideia de que o trabalhador deveria tornar-se objeto de exortações morais, isto é, "ao trabalhador recomenda-se o cultivo das virtudes, o que lhe permitiria deixar sua condição de inferioridade social. Mas àqueles já bem posicionados na hierarquia social, que são a concretização do sucesso econômico, não se permitiria a falta de responsabilidade social". Neste ponto, é interessante notar que, desde Smiles, já se constituía a ideia de que os homens bem-sucedidos economicamente devem apresentar comprometimento com a esfera social.

Martelli (2006) demonstra que o século XIX consolidou uma cultura moral dependente do conceito de dever, que procurou combinar o princípio da liberdade individual com as obrigações para com a coletividade. Para a autora, a condução da vida proposta pela autoajuda se baseava no exercício produtivo de uma profissão, no cultivo de virtudes morais e no comprometimento da responsabilidade pessoal com o progresso geral da sociedade. Tais ideais e justificações são ilustrativos do espírito que marca o capitalismo industrial (Boltanski, Chiapello, 1999).

Assim, de acordo com Smiles, segundo Rüdiger (1996), a ideia de self-made man indivíduo capaz de transpor todos os desafios e alcançar sucesso - é superada pela imagem do self-help man, aquele que tem como objetivo também reconstruir os valores morais da 
sociedade. A ideia de self-help man, portanto, passa a se diferenciar da autoajuda de origem inglesa, que, baseada na ética puritana, possibilitava a mobilidade social e o êxito pessoal. Bosco (2001) aponta que a temática da autoajuda na América do Norte deixa de pregar somente um crescimento moral, para tratar mais nitidamente da ascensão financeira. De acordo com essa corrente, é necessário ter um "bom caráter" para atingir a "salvação econômica", ou seja, a riqueza material do homem seria justificada pela aprovação divina atrelada ao desenvolvimento do bom caráter.

Vale retomar as análises de Max Weber $(1991,2001)$ sobre os escritos de Benjamin Franklin, que buscam dar conta do surgimento de uma nova ética religiosa em consonância com o desenvolvimento de uma nova ética econômica, apontada especificamente nos EUA. Na obra de Weber (2001), Franklin é considerado um representante da ética do trabalho e dos negócios, característica representativa do "espírito" capitalista que é, segundo Weber (2001), formado pelo protestantismo ascético.

Cabe ressaltar que os escritos de Franklin foram fundamentais e impulsionaram o avanço da literatura de autoajuda norte-americana. Ele é o autor do famoso Poor Richard's Almanack (1732), cujos provérbios, tais como "um tostão poupado é um tostão ganhado", até hoje são mencionados e conhecidos no mundo todo, como apresenta Oliven (2001, p.15) no trecho a seguir:

Benjamin Franklin (1706-1790), frequentemente exaltado como o primeiro norteamericano civilizado e o apóstolo dos tempos modernos, era entre outras coisas um inventor e um bem-sucedido homem de negócios. Ele se tornou famoso por causa dos seus 'provérbios'. Entre 1733 e 1758, publicou um almanaque que vendia dez mil cópias por ano. Embora Franklin não tenha criado a maioria dos provérbios publicados no seu Poor Richad's Almanack, como ele próprio deixava claro, eles ficaram associados à sua pessoa (destaque no original).

De acordo com Van Kessel (2006), um dos principais fatos que influenciaram Weber a escolher Benjamin Franklin como a personificação do "tipo ideal" do espírito do capitalismo se refere à sua visibilidade, que antecedeu o desenvolvimento social do capitalista, enfatizando o poder do "espírito" como fator causal na história. O espírito que Weber (2001) buscou descrever, portanto, não apenas motiva os indivíduos, mas pode também caracterizar e até mesmo marcar toda uma época cultural, econômica e socialmente (Van Kessel, 2006).

Isso posto, a autoajuda atingiu seu ápice nos EUA entre 1895 e 1915. O movimento, que ficou conhecido como "novo pensamento", pregava a transformação psicológica e espiritual do indivíduo por meio da força de seus pensamentos, unindo o entendimento de que "pensar é poder" à interpretação de que o sucesso é resultado de determinação, ambição, paciência e perseverança (Nunes, 3 set. 2002; McGee, 2005).

De modo geral, foi somente em 1936 que a autoajuda se consolidou nas prateleiras das livrarias. Isso se deu a partir do sucesso do livro Como fazer amigos e influenciar pessoas, de Dale Carnegie, um guia para comerciantes que oferece dicas práticas e exemplos para ilustrar como se deve enfrentar as situações do cotidiano (McGee, 2005). Os princípios de Dale Carnegie deram início a um circuito internacional de treinamento profissional, que oferece cursos e palestras e vende produtos de autoaperfeiçoamento. 
Para a socióloga Micki McGee (2005), Joseph Murphy - outro "clássico da autoajuda" que eclodiu pelo movimento do novo pensamento e ficou conhecido pelo livro O poder do subconsciente (1963) - defende que o subconsciente, ao aceitar uma ideia, começa imediatamente a colocá-la em prática. Murphy também é autor de O poder milagroso de alcançar riquezas infinitas (1975) e 1001 maneiras de enriquecer (1966), ambos sucessos de vendas que até hoje figuram nas prateleiras das livrarias (McGee, 2005).

De acordo com Effing (2009), a literatura de autoajuda representa um pilar básico da cultura norte-americana, tendo se consolidado a partir da ideia de trabalho e esforço com Benjamin Franklin. Essa noção perdurou até meados do século XX; após a Segunda Guerra Mundial, tal literatura se constitui por meio de uma cultura de "lazer e facilidade". Atualmente, consagra-se por sua ênfase no estudo do espírito e da mente para a conquista da felicidade e do sucesso. Podemos dizer que temos a ressonância desse desenvolvimento da autoajuda no Brasil (Rüdiger, 1996), já que desde o início do século XX até os dias atuais a maioria dos livros mais vendidos é tradução de autores norte-americanos (Leite, 2012).

Nesse trajeto de conformação moral dos indivíduos via arautos da autoajuda, tal fenômeno começa a se expandir para além das livrarias. Surgem, assim, técnicas e métodos que buscam colocar em prática os artifícios propostos pelos manuais, como o Método Silva, que surgiu no início do século XX e reúne um conjunto de técnicas para desenvolver as capacidades (inatas) que o ser humano possui mas não exercita.

Nesse sentido, o objetivo deste artigo é ilustrar os sentidos sociais da autoajuda e sua conformação moral por meio de um recorte bibliográfico da temática, que surge ligado, em especial, ao espírito do capitalismo industrial (Boltanski, Chiapello, 1999) e que passa a espraiar-se para outros circuitos de legitimação, como veremos a seguir.

\section{Os sentidos sociais de sua legitimação}

Nesse ínterim, segundo McGee (2005), a autoajuda associa-se à difusão das práticas terapêuticas, legitimando técnicas de autocontrole desenvolvidas para que o indivíduo supere problemas advindos de todas as esferas - profissional, familiar ou econômica. Essa ligação marca o "triunfo da terapêutica" sobre as estruturas religiosas e os valores espirituais, fenômeno estudado mais especificamente pelo historiador Philip Rieff (1990). De acordo com os estudos por ele desenvolvidos, o terapeuta passa a ser visto tanto como sucedâneo laico de uma religião quanto como representante de uma nova ética. A autoajuda, em consonância com as práticas terapêuticas e os métodos de organização do trabalho, constituise como técnica de doutrinação que passa a dar sentido ao mundo, como exemplifica Jacoby (1977, p.166) no trecho a seguir.

Hoje, místicos semiconvictos emparelham com outros totalmente convictos; estrelas, signos, gurus, interpretam um mundo de hieróglifos capitalistas. As mensagens das estrelas inadvertidamente dizem a verdade: o destino e a condição de cada dia são irracionais - está nas estrelas [aqui faz referência a The stars down to earth, de Adorno]. Portanto, elas aliviam aqueles que desconfiam que a vida é tão predeterminada quanto realmente é, transferindo a culpa da realidade social para a natural e sobrenatural. 
Alves (2005), por outro lado, afirma que a produção de autoajuda das décadas de 1930 e 1940 retoma a publicação de livros que promulgavam o retorno aos valores religiosos, ressuscitando a ética protestante, tais como The return to religion (Volta à religião), lançado em 1936 por Henry C. Link. Além dessa, outras obras tentavam conciliar religião e psicanálise. É o caso de Peace of mind (Paz de espírito), do rabino Joshua Liebman, publicado em 1946, em conjunto com outros livros que (re)estilizavam os preceitos do novo pensamento, como Quem pensa enriquece, de Napoleon Hill, lançado em 1937, e Como fazer amigos e influenciar pessoas, de Dale Carnegie, publicado em 1936 (Alves, 2005). Vale destacar que tais textos foram todos traduzidos para o português e até hoje são sinônimos de sucesso no Brasil.

Nesse percurso, a partir do século XX, a autoajuda se fortalece como prática terapêutica ligada à psicologia, configurando o que Castel (1987) denomina "autoajuda para normais". O referido autor, ao realizar um estudo da antipsiquiatria à pós-psicanálise, argumenta que, a partir das novas terapias - consideradas indústrias de transformação do capital humano -, passa a ser possível instrumentalizar a subjetividade e a intersubjetividade por meio de intervenções exteriores.

Essas terapias promovem uma visão do homem por meio da qual ele concebe a si próprio como possuidor de uma espécie de capital, capaz de gerar, para dele extrair, uma certa mais-valia de gozo e de capacidades relacionais (Castel, 1987). Ainda segundo Castel (1987, p.168), a psicologia passa a representar um papel homólogo ao da cirurgia estética, cuja finalidade é menos reparar os corpos do que lhes proporcionar a mais-valia da harmonia e da beleza: "As fronteiras entre o psicológico e o social se embaralham porque uma sociabilidade programada por técnicas psicológicas e relacionais representa o papel de substituto de um social em crise".

A partir da associação das técnicas de autoajuda às práticas terapêuticas, consolidamse métodos direcionados para que os indivíduos se adaptem e resolvam os problemas surgidos com as intensas mudanças ocasionadas pelo mundo do trabalho na modernidade. Jacoby (1977) realiza uma análise crítica da psicanálise conformista (pós-freudiana) como uma tendência cultural que gera a "amnésia social", uma vez que enfatiza o indivíduo como alguém aconselhado a cuidar de sua própria vida e buscar conforto nos manuais de autoajuda. Ou seja, "o indivíduo é levado a crer que com um pouco de autoajuda a alienação descerá pelo cano de esgoto como uma sujeira numa pia cintilante e imaculada" (Jacoby, 1977, p.81). É nesse espaço, segundo Jacoby, que as terapias passam a ser vendidas e consumidas como produtos; as teorias e métodos utilizam a marca da autoridade científica e são transformadas em palestras, cursos, workshops e livros. Esse fenômeno oferece uma explicação plausível sobre a atual situação do indivíduo e prescreve receitas que visam transformar a situação momentânea, que é sempre de fracasso, e adequar o tempo ao ritmo exigido pela era moderna.

Nesse sentido, as técnicas de autoajuda introduzem a ética que sedimenta o ideal de trabalho associado ao prazer. De acordo com McGee (2005, p.176), tal literatura também se adapta à cultura do autoaperfeiçoamento e aos valores do mundo competitivo impostos pelo mercado, transpondo tal ideário para o mundo da vida íntima, e vice-versa, como exemplifica no trecho a seguir, com base no contexto norte-americano. 
O apelo dessa literatura é compreensível: o enorme crescimento da publicação de livros de autoajuda é paralelo a uma tendência geral de salários estagnados e oportunidades de emprego desestabilizadas para trabalhadores americanos. Os americanos enfrentam o que alguns observadores sociais têm chamado de uma 'nova insegurança' na esteira do fim do trabalho e da família tradicionais. Com alguns programas de bem-estar social praticamente desmantelados, e com casamentos e profissões vitalícias tornando-se cada vez mais anacrônicos, não é mais suficiente estar casado ou empregado; em vez disso, é imperativo que se permaneça casável e empregável. Esculpir o próprio corpo para permanecer desejável ao esposo e aperfeiçoar as próprias técnicas de liderança para continuar a ser valorizado pela empresa não são opções, mas imperativos nessa nova economia. Uma sensação de segurança pessoal é anômala, enquanto a ansiedade é a norma. Para lidar com essa ansiedade, indivíduos têm sido aconselhados não apenas a trabalhar mais e por mais tempo, mas a investir em si mesmos, gerenciar a si mesmos e continuamente melhorar a si mesmos (McGee, 2005, p.12).

Assim, a autoajuda e as práticas terapêuticas surgem como "salvação" para os problemas do mundo contemporâneo, buscando o equilíbrio "entre as categorias da personalidade moral e do indivíduo egoísta, transmitidas pela alta modernidade" (Rüdiger, 1996, p.166). Isso posto, o referido autor argumenta que a literatura de autoajuda constitui uma das mediações pelas quais as pessoas procuram construir um "eu" de maneira reflexiva, gerenciando os recursos subjetivos para enfrentar os problemas trazidos pela modernidade (p.14).

Alves (2005) ressalta que a psicologia, porém, não é a única ciência em que muitos escritores de autoajuda buscam inspiração. A sociologia, a antropologia e principalmente a medicina e suas especialidades são outras importantes fontes dessa literatura. Desta última ciência e de outras que lhe são correlatas, Alves destaca os livros sobre dieta, que têm obtido enorme sucesso de vendas desde as últimas décadas do século XX, ao lado de obras sobre exercícios físicos, especificamente aqueles para manter "o cérebro em forma".

A partir das décadas de 1960 e 1970, percebe-se que a literatura de autoajuda está visivelmente enraizada na psicologia e na terapia, que passam a constituir-se como suas grandes fontes de informação, como elucida Bosco (2001). Tornando-se popular, a psicologia confunde-se com as técnicas de autoajuda, e vice-versa; tais métodos passam a ser empregados sobretudo para aperfeiçoar o trabalho dos indivíduos dentro das organizações, introduzindo-se, assim, também na área da administração.

Neste período os Estados Unidos são inundados com a autoajuda de caráter psicológico. A 'pop psychology' (Starker, 1989) anuncia que o sucesso pessoal não é somente a subordinação incondicional aos ditames das organizações e às exigências de ascensão individual, e prescreve que aspectos não imediatamente ligados à profissão, à economia ou a papéis sociais institucionalizados (família), devem ser primordialmente valorizados (Bosco, 2001, p.19; destaques no original).

A partir desse período, há uma grande ramificação do campo da autoajuda. A literatura produzida passa a abordar diversos setores, incluindo assuntos esotéricos, como a busca do eu interior e o desapego ao materialismo; aspectos organizacionais, ensinando de que maneira crescer dentro das corporações; questões emocionais, como a busca da felicidade, a conquista de um parceiro ou de que modo manter uma vida conjugal equilibrada; e sugestões sobre como alcançar o sucesso financeiro. Além disso, suas "verdades" são embasadas em diversos 
aspectos, como a religião, a crença, a fé, as terapias, a psicologia, o pensamento positivo, a magia, o misticismo e outras teorias. Para Bosco (2001), o indivíduo necessita de outro sujeito para se autoconhecer, reconhecendo na autoajuda um caráter de profissionalização. ${ }^{2}$

Assim, as capas dos livros de autoajuda exibem o número de edições em destaque, para expressar a ideia de que a quantidade é fator de legitimação e reconhecimento. Por outro lado, os discursos editoriais da contracapa remetem a críticas compostas por argumentos persuasivos, que tentam seduzir, e convincentes, uma vez que se apropriam de discursos científicos, filosóficos e religiosos. A argumentação correlaciona a situação presente do sujeito, que é sempre de fracasso, à possibilidade de reversão e de felicidade por meio de dicas, métodos e conselhos veiculados nos textos.

Segundo Asbahr (2005), a indústria cultural que está por trás da autoajuda não se circunscreve apenas à distribuição e venda de obras: há todo um aparato de divulgação tanto na mídia escrita quanto, em especial, na virtual - que incentiva, alimenta e prestigia as obras e seus escritores.

Para Illouz (2003), essa indústria dá cada vez mais ênfase à vida cotidiana, que passa a ser vista como uma arena de espetáculos, principalmente entre a classe média norte-americana, que tem cultivado a vida diária como espaço para a afirmação de uma identidade positiva. Cria-se um espectro de que a identidade e a moralidade são formadas e exercidas dentro do reino da vida diária, caracterizada pela crença no valor do êxito, da dignidade intrínseca do casamento e do medo da marginalidade. Assim, os talk-shows se apropriam de estímulos da autoajuda e tornam-se sinônimos de sucesso nos EUA, espraiando-se para o restante do mundo. O grande exemplo dessa febre é a figura de Oprah Winfrey, cuja dinâmica por ela própria operacionalizada reforça, segundo Illouz (2003), uma visão que responde ao caos e à insignificância, oferecendo um sistema "racional" de explicação do mundo.

No sentido aqui exposto, os conceitos desenvolvidos por Weber $(1991,2001)$ ainda são fundamentais para explicar o uso de sistemas racionais na cultura popular, o que responde também a "dilemas morais: como lidar com um mundo que consistentemente nos decepciona e como dar sentido às formas de sofrimento grandes e pequenas que afligem as vidas comuns" (Illouz, 2003, p.4). O sistema racional de explicação, empregado como técnica de autoajuda, consiste na combinação entre virtudes empreendedoras (como trabalho pesado, disciplina e inovação) e conselhos de guias espirituais. Dessa forma, de acordo com Illouz (2003), o "Oprah Show", por exemplo, apresenta um aspecto moral associado à autoajuda que engloba o sofrimento social como plataforma para auxiliar as pessoas a assumir responsabilidade com relação a suas próprias vidas. Essa visão tem como suporte o lado emocional, incitador do debate sobre ética e autoaperfeiçoamento.

Já os balanços de Hochschild (2003) acerca dos manuais de autoajuda mostram como, no decorrer da história, tais livros passaram de um padrão tradicional (os sentimentos adaptamse à ação) para um modelo mais igualitário, no qual a ação adapta-se ao sentimento (Bonelli, 2004). Empiricamente, no livro The commercialization of intimate life, a autora demonstra que os conflitos da vida íntima são reflexos das contradições da sociedade capitalista, isto é, o espírito do capitalismo entra na vida íntima e compete com a instituição familiar, afetando sobretudo as mulheres em seus papéis de mães e esposas. Essa dinâmica promove uma mistura entre padrões femininos e masculinos, entre o tipo de vida tradicional e o 
moderno. Tal associação é que garante o sucesso desse tipo de literatura, principalmente para o segmento feminino, uma vez que as mulheres precisam conviver com padrões tradicionais (mãe, esposa e dona de casa) e modernos (independência, autonomia e trabalho).

A revolução de gênero é causada sobretudo por mudanças na economia, mas as pessoas a sentem no casamento. De forma paralela, transformações econômicas têm sido o 'motor' da mudança nas relações entre brancos e negros. À medida que o número de empregos de baixa qualificação cai e o capital sai de cidades centrais para os subúrbios ou para a mão de obra barata em países de Terceiro Mundo, brancos e negros são deixados para competir pelos empregos restantes. Pode-se dizer que é nas salas dos fundos de bancos de investimento, nos escritórios de recursos humanos e nos salões de sindicatos que a tensão entre as raças tem origem. Mas é no pátio da escola, na prisão ou na rua que a tensão racial é de fato sentida. Assim como os negros americanos 'absorveram' uma taxa de desemprego mais alta 'pelos brancos', no mesmo sentido, o número crescente de mulheres que trabalham absorveu as demandas contraditórias da família e do trabalho 'pelos homens', trabalhando durante mais meses no ano. Se os negros diminuíram a taxa de desemprego para os brancos, as mulheres reduziram o conflito família-trabalho para os homens. Mas, ao contrário da maioria dos brancos e negros, homens e mulheres moram juntos; a absorção feminina de um problema masculino torna-se parte do casamento, e coloca tensão sobre ele (Hochschild, 1989, p.258; destaques no original).

Portanto, a literatura de autoajuda, para Hochschild, é um intermediário cultural que visa resolver os problemas cotidianos dos indivíduos, em especial das mulheres. Illouz (2007) também ilustra a importância do uso de tal clamor emocional em sintonia com o capitalismo, o que gera uma cultura na qual emoções e práticas econômicas moldam mutuamente umas às outras. Isso produz um movimento amplo e abrangente, em que o afeto torna-se o aspecto essencial do comportamento econômico e, por conseguinte, reforça o importante papel que a literatura de conselho, embasada na autoajuda, desempenha na transformação do selfindividual. É dessa forma que a autoajuda se constitui como sinônimo de sucesso.

Entretanto, a partir da visão sociológica sobre a temática exposta até o momento, uma breve explicação sobre o sucesso do ramo da autoajuda encontra ressonância no ideário de expansão do sistema capitalista e da busca pela cura de possíveis patologias produzidas pela dinâmica do mundo moderno (Rüdiger, 1996). Ao mesmo tempo, o espetáculo em torno de histórias de vida que motivam o constante autoaperfeiçoamento individual sustenta o sucesso de livros voltados para carreira e negócios, como afirmam Giardino (2005), Leite e Melo (2008), Oliveira (2006).

Atualmente, a literatura de pop-management, que faz apologia à competência do trabalhador (Wood Jr., 2001, p.87), é referência para empresários e trabalhadores. Nessa mesma linha, Chies e Marcon (2008) analisam a referida literatura como sendo a religião do trabalhador pós-moderno, já que se tornou um recurso utilizado pelos indivíduos para enfrentar a complexidade exigida pelo mundo do trabalho. Aqui, destacam-se os profetas do mundo dos negócios: Tom Peters, John Naisbitt e Gifford Pinchot, considerados herdeiros do clássico Peter Drucker, o pai da administração moderna. Eles elaboraram manuais de conduta que passaram a doutrinar o padrão de vida dos indivíduos e da sociedade (Chies, Marcon, 2008), da mesma forma como operam os manuais de gestão empresarial que foram 
estudados mais recentemente por Boltanski e Chiapelo (1999), entendidos como o motor que impulsiona o "novo espírito do capitalismo".

$\mathrm{O}$ antigo ideal deve ser removido para dar lugar a um novo profissional, comprometido com o trabalho e, principalmente, com seus resultados; o intraempreendedor, capaz de perceber e agir, "o apóstolo da excelência", segundo Wood Jr. (2001) e Paulo e Wood Jr. (2002, 2003). Assim, cunha-se a base para a construção de uma nova ética que alimenta o mundo do trabalho e sustenta a busca do sucesso individual, prescrevendo métodos que funcionam como novas formas de empregabilidade e "curas" para os males da pósmodernidade. É essa nova ética que, mais recentemente, passou a legitimar o mercado de coaching no mundo dos negócios (Picanço, 2013).

Já a pesquisa realizada por Pedroso Neto (2001) aborda o espaço dos colaboradores da Amway para explicar como se produz e se reproduz esse corpo de agentes que dinamizam e expandem suas redes de relações, constantemente conquistando novos adeptos ou associados. Nesse sentido, o autor argumenta que há um extensivo uso de práticas de autoajuda no treinamento dos agentes para que se tornem autoconfiantes e, mesmo em uma situação de fracasso, mostrem-se preparados e "otimistas" para procurar novas alternativas de inserção econômica (fora do modelo formal de empregabilidade) que antes eram invisíveis, segundo suas percepções.

Essas questões que apontam as incertezas trazidas pelo sistema capitalista - assinalando problemas referentes à duração média do trabalho, à renda econômica e ao aumento do custo de vida básico, ligado à saúde, à habitação e à educação - contribuem para a promoção de discussões que envolvem o planejamento financeiro e a poupança. Esses assuntos abrem espaço para a explosão da literatura sobre finanças pessoais, que, por sua vez, foi inicialmente categorizada como "autoajuda financeira" pela maioria das editoras e livrarias do país, como exemplifica o trecho a seguir, retirado de uma revista brasileira de economia.

Eis a febre do momento nas livrarias brasileiras. Apenas os 15 livros de finanças pessoais mais badalados já venderam 700 mil exemplares nos últimos três anos. $\mathrm{O}$ número é expressivo. No Brasil, são poucos os livros que ultrapassam a barreira das 5 mil unidades. O barulho extrapola as prateleiras das grandes redes. Os autores, populares, passaram a receber inúmeros e-mails de leitores ansiosos por uma consulta. Conseguiram espaço em colunas de jornais e nos programas de televisão. Viraram consultores e palestrantes de empresas e universidades. São estrelas (Pavon, jul. 2003).

A autoajuda financeira também concorre com outros segmentos, incluindo bem-estar, esportes, espiritualismo, negócios, saúde etc. Entretanto, hoje em dia ela é um fenômeno de destaque nas livrarias brasileiras. Nesse cenário, as estrelas são os consultores financeiros, que aliam aconselhamento psicológico e financeiro. Segundo McGee (2005), princípios racionais e econômicos passam a interferir cada vez mais na esfera privada por meio dos gurus das finanças. Um exemplo mencionado pela autora é o caso de uma das conselheiras mais famosas dos EUA, Suze Orman, que também possui seu próprio talk-show e é abençoada pelas mãos de Oprah.

Quando Orman fala sobre investir dinheiro de forma que 'ele trabalhe para você', ela está descrevendo a maneira pela qual a receita de juros e dividendos é derivada da 
expansão da economia, que é, claro, dependente da produtividade dos trabalhadores. Assim, quando o dinheiro de um investidor 'trabalha' para ele, em algum lugar alguém está trabalhando e levando para casa menos do que o valor do que ele ou ela produziu em seu dia de trabalho. Ou ainda, mais valor pelo qual ele ou ela não é recompensado. A única saída para este dilema - na visão de Orman - é que os trabalhadores economizem e acumulem dinheiro de maneira a se tornarem investidores por si mesmos e assim recuperarem algo do que lhes foi apropriado (McGee, 2005, p.109; destaques no original).

Nesse ponto, Fridman (2017) elucida tal momento de legitimação da autoajuda nos EUA e sua sintonia com o ideário neoliberal, em que o valor moral é o valor do dólar. Assim, o mundo da autoajuda financeira sugere que são os indivíduos que devem mudar, no caso, libertar-se do mundo do trabalho, alimentando o sonho da liberdade financeira. Nesse sentido, Leite (2012) aponta como a autoajuda financeira ganha repercussão no Brasil - em especial a partir da tradução da obra norte-americana Pai rico, pai pobre -, consagrando-se o ramo editorial conhecido como finanças pessoais.

Para Rüdiger (1996), portanto, a literatura de autoajuda tornou-se uma espécie de síntese ética da composição de tendências do avanço do capitalismo, que propiciaram a transformação da personalidade em categoria social no contexto do individualismo contemporâneo. Nesse sentido, Asbahr (2005) enfatiza que essa literatura oferece certo referencial ético em meio a um contexto de descrença trazido pelos ares do capitalismo.

O fenômeno da autoajuda torna-se, então, a expressão do individualismo da sociedade contemporânea, estabelecendo a regra moral do comportamento individual (Rüdiger, 1996). Do mesmo modo, a análise de Chagas (2001) também revela a idiossincrasia manifestada pelo imaginário individualista elucidado pelo movimento da autoajuda, no qual o sujeito se vê em um imaginário narcísico, conforme enfatizam Magro e Martelli (2006, p.272) no excerto abaixo.

Não há nada de errado com o mundo. É você que tem que mudar, e não o mundo - professam os manuais. Por esse viés, os discursos de autoajuda assumiriam, então, um papel singular na medida em que ajudariam a construir um modelo econômico, político, social e moral de sociedade, que se afinaria com os valores da sociedade capitalista atual. Assim, o fenômeno da autoajuda não só traduziria como também reforçaria as demandas da sociedade.

Nesse sentido, Douglas (1998) e Grün (2003) alertam que tanto escritores quanto leitores de autoajuda passam a compartilhar uma mesma crença: a de que é possível produzir, pouco a pouco, uma mudança cultural que busque transformar práticas e percepções acerca do mundo em que vivemos.

Por outro lado, tal fenômeno também passa a ser justificado pelos intelectuais da modernidade. Teóricos como Giddens (2002) partem das consequências da modernidade para explicar por que os indivíduos consomem terapias e manuais de autoajuda. Para o autor, tais manuais, livros de caráter prático, refletem e constroem a reflexividade da sociedade moderna: "O eu é para todos um projeto reflexivo ... É um projeto conduzido em meio a uma profusão de recursos reflexivos: terapia e manuais de autoajuda de todo os tipos, programas de televisão e artigos de revistas" (Giddens, 1993, p.41). 
Assim, pressupõe-se que, ao tentar desestruturar laços tradicionais, a modernidade proferida pelos manuais de autoajuda desestabiliza o indivíduo, gerando a fuga para a interioridade. Nessa condição, o eu interior busca a identidade entre as estratégias e opções fornecidas pela confiança nos sistemas abstratos. Estes, por sua vez, acabam legitimando o sucesso da literatura de autoajuda em consonância com o desenvolvimento do capitalismo (Giddens, 1997).

Segundo Demo (2005), a autoajuda pode até ter um lado sábio porque propõe apoio para os indivíduos lidarem com problemas insuperáveis e deles exigir uma atitude mais conformada perante a realidade. Entretanto, o autor enfatiza que a autoajuda se reduz a uma "estratégia de espoliação da boa vontade ou da ignorância dos outros" (p.102). Assim, ao propor uma teoria crítica sobre a autoajuda - chamando a atenção para uma sociologia da ingenuidade como condição humana -, o autor destaca que ela "é fraudulenta, de um lado por ser propaganda enganosa, e de outro, por implicar atrelamentos que nada têm a ver com alguém que saberia 'autoajudar-se'” (p.103; destaque no original).

Ao explorar a questão da autoajuda na mídia, Asbahr (2005) argumenta que é possível encontrar diversos posicionamentos acerca dos livros que tratam do assunto, tanto em periódicos de circulação regional como nos de grande abrangência nacional. Jornais e revistas ora apresentam os livros de autoajuda como úteis, destacando a importância que podem assumir na vida de seus leitores, ora trazem uma problematização da necessidade e da importância desse tipo de literatura na sociedade atual, apresentando-a como um gênero menor, em tom crítico, como um engano ou "charlatanismo" (Asbahr, 2005, p.17).

De modo geral, a revisão bibliográfica sobre a literatura de autoajuda mostra que ela acompanha o percurso capitalista e se apropria de artifícios de legitimação, como a terapia e a psicologia (Castel, 1987; Illouz, 2007; Jacoby, 1977; Rieff, 1990; McGee, 2005; Chagas, 2001, 2002). Esses recursos propiciam armas e conforto para que os indivíduos possam conviver com os percalços e/ou patologias criados pelo próprio capitalismo e pela modernidade (Giddens, 1997; Hochschild, 2003).

Entretanto, a revisão elencada até o momento nos permite ir além de análises superficiais, que criticam o segmento de autoajuda por apresentar métodos ou técnicas de doutrinação que buscam adaptar os indivíduos às características da vida moderna, mantendo-os alienados e incapazes de refletir sobre suas próprias decisões. Essas análises parecem prescrever um apelo ao individualismo propagado pelos próprios teóricos e críticos desse tipo de literatura.

De forma grosseira e sem ares analíticos, vale ressalvar que as ideias de autonomia, liberdade e autoaperfeiçoamento encontradas nos manuais de autoajuda estão em harmonia com uma identidade-nós (Elias, 1994). Isto é, se os livros de autoajuda são bestsellers e constituem uma síntese ética do momento histórico, pode-se dizer que há receitas individuais - busca da identidade-eu - em massa que constituem uma identidade-nós. A partir desse simples panorama, a teoria de Elias $(1986,1994)$ surge como uma grande aliada para analisar o movimento da autoajuda e assim explicar as formas de adaptação de indivíduos, tanto social quanto moralmente, sem prescrever comportamentos moldados por uma espécie de segunda natureza, conforme descrito por críticas levianas a respeito do fenômeno da autoajuda. 
Segundo Elias (1994), o termo "indivíduo" vem associado à ideia de que todo ser humano deve constituir uma entidade autônoma, diferente dos demais. Em suas próprias palavras, "é característico da estrutura das sociedades mais desenvolvidas de nossa época que as diferenças entre as pessoas, sua identidade-eu, sejam mais altamente valorizadas do que aquilo que elas têm em comum, sua identidade-nós" (p.130).

Para Elias $(1986,1994)$, os analistas sociais falham por considerar a dicotomia indivíduo/ sociedade algo estático, já que, ao analisar o papel do indivíduo de forma isolada, obtêm-se os seguintes resultados: de um lado, uma imagem negativa dos indivíduos, que são tidos como "implacáveis e brutais, propensos a oprimir os outros e a enriquecer à custa deles" (Elias, 1994, p.74); de outro, uma imagem positiva, em que a "palavra indivíduo pode estar associada ao orgulho por sua posição independente na sociedade", conquistada por méritos próprios (p.75).

A maioria das análises sobre o fenômeno da autoajuda costuma retratar os indivíduos e suas atuações como característicos das sociedades modernas, concretizando uma profecia autorrealizante. Ao mesmo tempo que criticam o referido fenômeno, também o legitimam como prática dos tempos atuais, já que ora o indivíduo é visto como alienado por consumir autoajuda, ora é concebido como egoísta por utilizá-la para o seu próprio desenvolvimento. Assim, os referidos autores ilustram uma sociologia da autoajuda que nos ajuda a escapar das armadilhas heurísticas do próprio fenômeno.

\section{Considerações finais: para além da crítica}

O cerne deste artigo foi uma breve revisão bibliográfica acerca da temática da autoajuda, a partir de um rastreamento sobre a origem do conceito e sua ligação com as demais temáticas e áreas acadêmicas responsáveis pela construção social e consagração moral do que vem a ser o fenômeno da autoajuda nos dias atuais.

Ao evitar a linguagem escolástica, a revisão bibliográfica apresentada procura demonstrar que o fenômeno da autoajuda acompanha o percurso do mundo do trabalho e do sistema capitalista e apropria-se de artifícios de legitimação, como a terapia e a psicologia (Castel, 1987; Illouz, 2003; Jacoby, 1977; Rieff, 1990; McGee, 2005; Chagas, 2001, 2002). O segmento também encontra ressonância no campo da administração (Wood Jr., 2001; Paula, Wood Jr., 2002, 2003) e das finanças pessoais (Leite, 2012), tornando-se um importante ramo editorial. Por outro lado, não se pode deixar de mencionar a importância de alguns teóricos que foram resgatados para demonstrar os caminhos pelos quais é possível abordar a temática da autoajuda (Giddens, 1997; Hochschild, 2003; Magro, Martelli, 2006) para além da crítica supérflua.

A despeito das particularidades existentes e dos contextos específicos nos quais os discursos de autoajuda se difundem, o objetivo deste artigo foi apontar um desenvolvimento histórico e sociológico a respeito do tema. No geral, podemos enfatizar que as análises acadêmicas sobre ele são carregadas de críticas, transformando-o em mais uma fatalidade a ser condenada pelos intelectuais. Aqui, o foco foi atentar para a crítica que se centraliza nas consequências perversas de sua magia, que parecem impossíveis de ser combatidas (ver Grün, 2003). Assim, reforçamos a importância de análises heurísticas acerca do fenômeno da autoajuda, buscando traçar sua historicidade, bem como alertar sobre suas consequências sociais. 
De modo geral, o recorte teórico exposto remete ao quadro do processo civilizador estudado por Elias $(1993,1994)$, no qual é possível observar a construção de dois mundos divergentes de pensamento. O primeiro é formado por aqueles que dão força ao campo, isto é, os próprios escritores e difusores do gênero de autoajuda. O segundo é constituído por uma elite pensante que cria um modelo próprio sobre como o conceito de autoajuda deve ser pensado. Os teóricos muitas vezes não atentam para a própria sociologia do mundo intelectual, que tem como objetivo analisar tanto aspectos relacionais quanto processuais do fenômeno em questão (Pontes, 1997).

Elias aponta que os novos padrões de comportamento estabelecidos pelos manuais que percorriam a sociedade de corte francesa deixaram de ser conscientes para se tornar uma segunda natureza. É a essa segunda natureza que o autor se refere quando fala em mudanças na estrutura da personalidade, isto é, na transformação das estruturas psíquicas (habitus) do indivíduo, tanto do senso comum como dos próprios intelectuais. Assim, tem-se que a decorrência do desenvolvimento de novas funções sociais interdependentes dá lugar a uma nova economia psíquica que constitui a sociedade em geral.

Cabe ressaltar, segundo Bennett (2011), a importância que o ideário do "otimismo" assume nos dias atuais. A emergência desse conceito - que reforça o imaginário social de que o indíviduo deve buscar forças para superar fracassos e atingir o sucesso - está simbolicamente atrelada ao fenomêno da autoajuda. Nesse ponto, a sociologia processual e relacional de Elias se torna instigante, pois alerta para a observação do avanço da autoajuda com relação às estruturas que se movem entre indivíduo e sociedade.

De acordo com Preda (2006), a sociedade de corte estudada por Elias estava envolvida em redes de posições sociais, regras e forças nas quais os selves individuais eram moldados pelas regras determinantes do processo de interação. O self (ver Goffman, 1953) não é uma criação isolada, mas uma "figura" situada na rede de interações, onde outros agentes também exercem forças.

Segundo Leite (2012), o que se observa são agentes que passam a se comportar a partir da lógica argumentativa propalada por tais especialistas (ver Bourdieu, 2004) em consonância com dispositivos culturais que operam conjuntamente na sociedade. Portanto, se há, de um lado, os "profetas" desse discurso, por outro há também uma sociedade receptiva a acatar (Grün, 2007) os conselhos e práticas produzidos por tais agentes (Leite, 2012).

No entanto, por meio dos ideais expressos no discurso da autoajuda, é possível observar que, subjetivamente, temos a construção social de sujeitos com disposição para atuar moralmente de forma reconhecida como "boa e justa". De modo geral, as técnicas que buscam redirecionar metas e valores induzem à performatividade da ação do indivíduo como um caminho para o desenvolvimento do self, gerando dinâmicas e sensibilidades específicas e configurando novas realidades sociais. Assim, a complexidade do fenômeno pode produzir análises contaminadas por conceitos teóricos que tratam a autoajuda como uma literatura trivial e com consequências perversas para o indivíduo e a sociedade. 


\section{NOTAS}

${ }^{1}$ Nessa e nas demais citações de textos em inglês, a tradução é livre.

${ }^{2}$ Além do ramo específico da literatura de autoajuda, vale destacar a ascensão da profissionalização de alguns serviços direcionados estritamente a indivíduos que procuram transformar (na prática) as suas vidas. Um exemplo é a consolidação do mercado de personals (personal trainer, personal stylist, personal xamã), como é apontado pelo trabalho de Dios (2017).

${ }^{3}$ Vale ressaltar que muitas vezes o indivíduo nem mesmo se sente fracassado, mas a "magia" propalada em torno dos livros de autoajuda acaba por induzi-lo a encontrar um problema, ou mesmo a transformar uma atitude rotineira em problema. Aqui cabe reproduzir um trecho de entrevista com a escritora americana Barbara Ehrenreich, que se declara contrária à autoajuda ou ao chamado pensamento positivo: “Um estudo recente mostrou que desde 1972 as mulheres estão cada vez mais tristes nos Estados Unidos e em outros países industrializados. Você lê isso e pensa: talvez eu não seja tão feliz como deveria ser. E, então, adivinha! Imediatamente após a publicação do estudo, lançam um livro (que comprei) chamado ‘Encontre o melhor momento de sua vida agora: o que as mulheres mais felizes e bem-sucedidas fazem de diferente'. É um livro típico de autoajuda, com testes de personalidade e anúncios de outros produtos que você pode comprar. Ou seja, o problema é criado e depois se oferece uma solução" (Magro, 18 nov. 2009).

\section{REFERÊNCIAS}

ALVES, Vera Lucia Pereira.

Receitas para a conjugalidade: uma análise da literatura de autoajuda. Tese (Doutorado em Educação) - Universidade Estadual de Campinas, Campinas. 2005.

ASBAHR, Melissa Cristina Correa. Os professores leitores dos livros de autoajuda para crianças. Dissertação (Mestrado em Educação) Universidade Estadual de Campinas, Campinas. 2005.

BENNETT, Oliver.

Cultures of optimism. Cultural Sociology, v.5, n.2, p.301-320. 2011.

BOLTANSKI, Luc; CHIAPELLO, Eva. Le nouvel esprit du capitalisme. Paris: Gallimard. 1999.

BONELLI, Maria da Glória.

Arlie Russell Hochschild e a sociologia das emoções. Cadernos Pagu, n.22, p.357-372. 2004.

BOSCO, Angelo Marcos.

Sucessos que não ocorrem por acaso: literaturas de autoajuda. Dissertação (Mestrado em Sociologia) - Universidade Estadual de Campinas,

Campinas. 2001.

BOURDIEU, Pierre.

A produção da crença: contribuição para uma economia dos bens simbólicos. Trad. Guilherme João de Freitas Teixeira. São Paulo: Zouk. 2004.

BRUNHELLI, Anna Flora.

O sucesso está em suas mãos: análise do discurso de autoajuda. Tese (Doutorado em Linguística) Universidade Estadual de Campinas, Campinas. 2004.
CASTEL, Robert.

A gestão dos riscos: da antipsiquiatria à póspsicanálise. Rio de Janeiro: Francisco Alves. 1987.

CHAGAS, Arnaldo.

O sujeito imaginário no discurso de autoajuda. Ijuí: Unijuí. 2002.

CHAGAS, Arnaldo.

A ilusão no discurso de autoajuda e o sintoma social. Ijuí: Unijuí. 2001.

CHIES, Zandomeneghi; MARCON, Silvana Regina Ampessan.

Literatura de pop-management: a religião do trabalhador pós-moderno. Contemporânea: Psicanálise e Transdisciplinaridade, n.6. Disponível em: <www.contemporaneo.org.br/contemporanea. php>. Acesso em: dez. 2016. 2008.

DEMO, Pedro.

Autoajuda: uma sociologia da ingenuidade como condição humana. Vozes: Petrópolis. 2005.

DIOS, Maria Luísa Célia Escalona de.

Chama o personal: estudo etnográfico sobre consultorias pessoais. Tese (Doutorado em Ciências Sociais) - Pontifícia Universidade Católica do Rio Grande do Sul, Porto Alegre. 2017.

DOUGLAS, Mary.

Como as instituições pensam. São Paulo: Edusp. 1998.

EFFING, M.M.

The origin and development of self-help literature in the United States: the concept of success and happiness, an overview. Journal of the Spanish Association of Anglo-American Studies, v.31, p.125-141. 2009. 
ELIAS, Norbert.

A sociedade dos indivíduos. Rio de Janeiro: Zahar. 1994.

ELIAS, Norbert.

O processo civilizador: uma história dos costumes. Rio de Janeiro: Jorge Zahar. v.1. 1993.

ELIAS, Norbert.

A sociedade de corte. Trad. Ana Maria Alves.

Lisboa: Estampa. 1986.

FRIDMAN, Daniel.

Freedom from work: embracing financial self-help in the United States and Argentina. New York:

Stanford University Press. 2017.

GIARDINO, Andrea.

Como os gurus brasileiros conquistaram seu espaço. Valor Econômico, 20 mar. 2005.

Disponível em: <https://www.valor.com.br/ arquivo/1000144421/como-os-gurus-brasileirosconquistaram-seu-espaco>. Acesso em: dez 2016. 2005.

GIDDENS, Anthony.

Modernidade e identidade. Rio de Janeiro: Zahar. 2002.

GIDDENS, Anthony.

A vida em uma sociedade pós-tradicional.

In: Beck, U.; Giddens, A.; Lash, S. (Org.).

Modernização reflexiva. São Paulo: Unesp Editora. p.73-134. 1997.

GIDDENS, Anthony.

A transformação da intimidade. Rio de Janeiro:

Zahar. 1993.

GOFFMAN, Erving.

The presentation of self in everyday life. New York: Doubleday. 1953.

GRÜN, Roberto.

Decifra-me ou te devoro! As finanças e a sociedade brasileira. Mana, v.13, n.2, p.381-410. 2007.

GRÜN, Roberto.

Atores e ações na construção da governança corporativa brasileira. Revista Brasileira de Ciências Sociais, v.18, n.52, p.139-161. 2003.

HOCHSCHILD, Arlie R.

The commercialization of intimate life. Berkley: University of California Press. p.1-103. 2003.

HOCHSCHILD, Arlie R.

The second shift: working parents and the revolution at home. New York: Viking. 1989.

ILLOUZ, Eva.

Cold intimacies: the making of emotional capitalism. London: Polity Press. 2007.
ILLOUZ, Eva.

Oprah Winfrey and the glamour of misery: an essay on popular culture. New York: Columbia University Press. 2003.

JACOBY, Russell.

Amnésia social: uma crítica à psicologia conformista de Adler a Laing. Rio de Janeiro: Zahar. 1977.

LEITE, Elaine da Silveira.

Reconversão de habitus: o advento do ideário de investimento no Brasil. Tese (Doutorado em Sociologia) - Universidade Federal de São Carlos, São Carlos. 2012.

LEITE, Elaine da Silveira; MELO, Natália Maximo.

Uma nova noção de empresário: a naturalização do "empreendedor". Revista de Sociologia e Política, v.16, n.31. 2008.

MAGRO, Maíra.

"Abaixo a ditadura do pensamento positivo". Isto É, n.2088. Disponível em: <https://istoe.com. br/9062_ABAIXO+A+DITADURA+DO+PENSAM ENTO+POSITIVO+>. Acesso em: 6 ago 2019. 18 nov. 2009.

MAGRO, Maíra; MARTELLI, Carla Giani. Autoajuda e gestão de negócios: uma parceria de sucesso. Rio de Janeiro: Azougue. 2006.

McGEE, Micki.

Self-Help, Inc.: makeover culture in American life. London: Oxford University Press. 2005.

NUNES, Glauciana.

Sucesso ou fracasso: autoajuda como solução ou ilusão? Trabalho apresentado no 25. Congresso Anual em Ciência da Comunicação, Salvador. 3 set. 2002 .

OLIVEIRA, Sheila Fernandes Pimenta. Discurso, gênero e argumentação na autoajuda de Shinyashiki. Tese (Doutorado em Letras) - Universidade Estadual Paulista "Júlio de Mesquita Filho", Araraquara. 2006.

OLIVEN, Ruben George.

De olho no dinheiro nos Estados Unidos. Estudos Históricos, n.27, p.206-235. 2001.

PAULA, Ana Paula Paes de; WOOD JR., Thomaz. Viagem epistemológica às livrarias dos aeroportos. Revista Administração em Diálogo, n.5, p.77-86. 2003.

PAUlA, Ana Paula Paes de; WOOD JR., Thomaz. Pop-management: contos de paixão, lucro e poder. In: Encontro de Estudos Organizacionais, 2002, Recife. Anais... Recife: Observatório da Realidade Organizacional; Propad/UFPE; Anpad. 2002. 
PAVON, Paula.

Passos para a fortuna. Isto é Dinheiro. Disponível em: <https://www.istoedinheiro.com.br/ noticias/investidores/20030730/passos-parafortuna/19202>. Acesso em: 19 jun. 2016. 30 jul. 2003.

PEDROSO NETO, Antonio José.

A reprodução da coesão organizacional na Amway. Dissertação (Mestrado em Ciências Sociais) Universidade Federal de São Carlos, São Carlos. 2001.

PICANÇO, Monise F.

O poder da solução: a construção do mercado de literatura de autoajuda (voltada a negócios). Dissertação (Mestrado em Sociologia) Universidade de São Paulo, São Paulo. 2013.

PONTES, Heloísa.

Elias, renovador da ciência social. In: Neiburg, Federico et al. Dossiê Norbert Elias. São Paulo: Edusp. p.17-36. 1997.

PREDA, Alex.

The investor as a cultural figure of global capitalism. In: Cetina, Karin Knorr; Preda, Alex (Ed.). The sociology of financial markets. New York: Oxford University Press. p.141-162. 2006.
RIEFF, Philip.

O triunfo da terapêutica. São Paulo: Brasiliense. 1990.

RÜDIGER, Francisco.

Literatura de autoajuda e individualismo. Porto Alegre: Editora da UFRGS. 1996.

SMILES, Samuel.

Self-Help. Disponível em <https://www.

gutenberg.org/ebooks/935>. Acesso em: 10 set. 2016. 1859.

VAN KESSEL, J.H.J.

Benjamin Franklin: the personification of Max Weber's "spirit of capitalism". Disponível em: <http://ideashistory.org.ru/pdfs/a31. pdf\#page=150>. Acesso em: dez. 2016. 2006.

WEBER, Max.

A ética protestante e o espírito do capitalismo. São Paulo: Martin Claret. 2001.

WEBER, Max.

Economia e sociedade: fundamentos da sociologia compreensiva. Brasília: UnB. 1991.

WOOD JR., Thomaz.

Organizações espetaculares. Rio de Janeiro: Editora FGV. 2001. 